\section{Bowman's capsule rupture on renal biopsy improves the outcome prediction of ANCA- associated glomerulonephritis classifications}

We read the published article by Gercik et al ${ }^{1}$ with great interest. In their retrospective study, they tested the existing classification systems to predict the progression to end-stage renal disease of patients with renal involvement by anti-neutrophil cytoplasmic antibody-associated vasculitis (AAV), demonstrating a better performance of the AAV renal risk score (ARRS) proposed by Brix $e t a l^{2}$ as compared with the 4-tiered glomerulocentric histological Berden's classification. ${ }^{3}$ They suggested that the employment of baseline glomerular filtration rate in the ARRS can partly represent a possible explanation for these results. However, the evaluation of extra-glomerular histological parameters that strongly correlate with the renal outcome ${ }^{4}$ (eg, interstitial fibrosis/tubular atrophy (IFTA)), can play a further role in the improvement of the ARRS performance. In this setting, many other classifications demonstrated the putative role of disparate histological features to predict the outcome of patients with primary (eg, IgA nephropathy ${ }^{5}$ ) and secondary (eg, lupus nephritis ${ }^{6}$ ) renal diseases, suggesting the possibility to further increase the prognostic role of the existing classification for AAV.

We retrospectively evaluated the performances of the currently used systems and investigated whether additional histological features can improve prognostic workflow of AAV. For this purpose, a retrospective, multicentric series of AAV cases have been reviewed. Each case has been independently evaluated by two renal pathologists, and classified according to the Berden's scheme and ARRS. Additional glomerular, tubulointerstitial and vascular lesions have been recorded for each case, following the previously provided definitions. ${ }^{78}$ The outcome of interest was time to need for renal replacement therapy (RRT) or death, whatever occurred first. Cox proportional hazards regression models were constructed with time to composite event, loss to follow-up or censoring (30 June 2019). Time at risk started at the date of renal biopsy. The histological features, collapsed into binary variables ( 0 to $1=$ low; 2 to $3=$ high $)$ and subdivided as 'active' (cellular/fibrocellular crescents, endocapillary hypercellularity, fibrinoid necrosis and Bowman's capsule rupture (BCR)) and 'chronic' (global glomerulosclerosis, fibrous crescents, segmental glomerulosclerosis, IFTA and arteriosclerosis) have been evaluated individually and in association with the currently proposed systems to assess their ability to predict the outcome. Univariate and multivariate models (HRs and 95\% CIs) have been used to assess the prognostic performance of Berden's class/ARRS alone and with additional predictors (Harrell's c-statistic).

After the selection of cases with available renal biopsy, complete clinical data (at least 6 months of follow-up) and positive anti-neutrophil cytoplasmic antibody (ANCA), 52 patients have been analysed (30 (58\%) males, median age 68 years (IQR 58 to 75$)$ ). ANCA showed myeloperoxidase (MPO) specificity in $31(60 \%)$ and PR3 in $21(31 \%)$, with a median titre of $101 \mathrm{U} /$ $\mathrm{mL}$ (IQR 55 to 264). Six patients (12\%) required dialysis at the time of the diagnosis. After the biopsy, 47 (90\%) patients were treated with corticosteroids, 34 (66\%) with additional immunosuppression and/or plasmapheresis $(8(15 \%))$. During a median follow-up of 31 months (1828 person-months), 13 composite events developed ( 8 deaths, 5 RRT). Sixteen (31\%) cases were classified as Focal, $8(15 \%)$ as Crescentic, $24(46 \%)$ as Mixed and $4(8 \%)$ as Sclerotic. Patients were grouped as low $(n=21$, $40 \%)$, medium $(n=24,46 \%)$ and high risk $(n=7,13 \%)$ based on

\begin{tabular}{|c|c|c|c|}
\hline \multicolumn{2}{|l|}{ Predictor } & HR $(95 \% \mathrm{Cl})$ & $p$-value \\
\hline \multicolumn{4}{|l|}{ Univariate analysis } \\
\hline \multicolumn{4}{|l|}{ Active lesions } \\
\hline \multicolumn{2}{|c|}{ Endocapillary hypercellularity } & $1.47(0.32$ to 6.72$)$ & 0.62 \\
\hline \multicolumn{2}{|c|}{ Cellular/fibrocellular crescents } & $1.68(0.55$ to 5.15$)$ & 0.36 \\
\hline \multicolumn{2}{|c|}{ Glomerular fibrinoid necrosis } & 0.62 (0.14 to 2.78$)$ & 0.53 \\
\hline \multicolumn{2}{|l|}{ Bowman's capsule rupture } & 3.71 (1.20 to 11.44$)$ & 0.023 \\
\hline \multicolumn{4}{|l|}{ Chronic lesions } \\
\hline \multicolumn{2}{|l|}{ Global glomerulosclerosis } & $1.49(0.50$ to 4.45$)$ & 0.47 \\
\hline \multicolumn{2}{|l|}{ Fibrous crescent } & 2.08 (0.63 to 6.84$)$ & 0.23 \\
\hline \multicolumn{2}{|l|}{ Segmental sclerosis } & 2.45 (0.79 to 7.58$)$ & 0.12 \\
\hline \multicolumn{2}{|c|}{ Interstitial fibrosis/tubular atrophy } & $1.26(0.27$ to 5.88$)$ & 0.77 \\
\hline \multicolumn{2}{|l|}{ Arteriosclerosis } & 2.79 (0.91 to 8.56) & 0.07 \\
\hline \multicolumn{4}{|c|}{$\begin{array}{l}\text { Univariate analysis on the active/chronic lesions with reported HR and } 95 \% \mathrm{Cls} \text {. } \\
\text { Statistically significant differences are reported with a bold p-value. }\end{array}$} \\
\hline Predictor & $\begin{array}{l}\text { Harrell's } \\
\text { c-statistic }\end{array}$ & $\mathrm{HR}(95 \% \mathrm{Cl})$ & Pp-value \\
\hline \multicolumn{4}{|l|}{ Multivariate analysis } \\
\hline Berden's class only & 0.67 & 3.61 (1.15 to 11.34$)$ & 0.028 \\
\hline Berden's class $+\mathrm{BCR}$ & 0.76 & & \\
\hline Renal risk score (Brix) only & 0.62 & 5.25 (1.53 to 18.08$)$ & 0.009 \\
\hline Renal risk score $+\mathrm{BCR}$ & 0.73 & & \\
\hline
\end{tabular}

Prognostic performance (with relative Harrell's c-statistic) of Berden's classes and Brix risk groups with/without the Bowman's capsule rupture (BCR) assessment and relative multivariate analysis. Statistically significant differences are reported with a bold p-value.

ARRS. Among the histological predictors tested (table 1), only BCR was significantly associated with the outcome at the univariate analysis $(p=0.023)$. Its addition (figure 1$)$ to the model, which included only Berden's class $(c=0.67)$ or ARRS $(c=0.62)$, significantly improved the prognostic performance $(c=0.76$ and

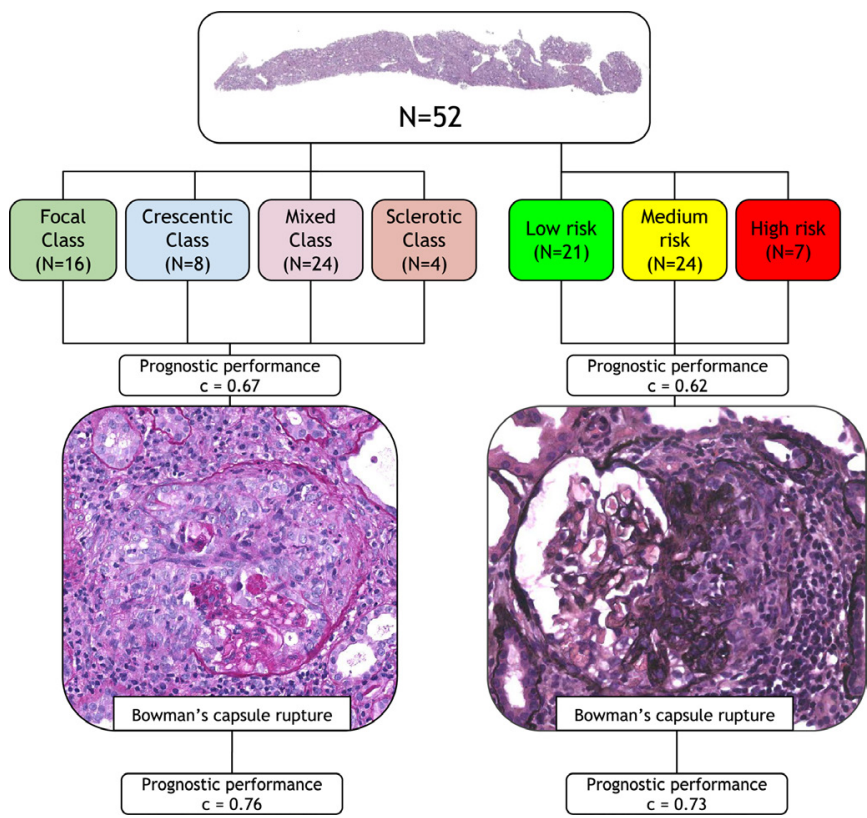

Figure 1 Panel depicting the improvement in prognostic performance of both the Berden's classification system ( $c=0.67)$ and the renal risk groups system proposed by Brix et al ( $c=0.62)$ after the addition of Bowman's capsule rupture as an ancillary parameter of acute renal damage ( $c=0.76$ and $c=0.73$, respectively). 
0.73 , respectively). This has been confirmed in the multivariate model which includes Berden's class (HR 3.61, 95\% CI 1.15 to 11.34; $\mathrm{p}=0.028$ ) and ARRS (HR 5.25, 95\% CI 1.53 to 18.08 ; $\mathrm{p}=0.009$ ). The present study demonstrates an improved performance of prognostic systems in predicting AAV outcome after the implementation of BCR, the additional predictive role of which can partly lie in the irreversible loss of nephrons consequent to the segmental glomerulosclerosis caused by BCR. ${ }^{9}$ Further investigations on a larger prospective cohort are required to confirm these results.

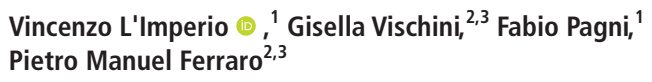

Correspondence to Dr Vincenzo L'Imperio, Pathology, Università degli Studi di Milano-Bicocca, Milano 20126, Italy; vincenzo.limperio@gmail.com

Twitter Vincenzo L'Imperio @VLimperioMD

Contributors VL ideated the study; VL and GV provided the retrospective histological assessment of renal biopsies; MF performed the statistical analysis; VL and FP drafted the paper; all the authors approved and revised the final version of the manuscript.

Funding The authors have not declared a specific grant for this research from any funding agency in the public, commercial or not-for-profit sectors.

Competing interests None declared.

Patient and public involvement Patients and/or the public were not involved in the design, or conduct, or reporting or dissemination plans of this research.

Patient consent for publication Not required.

Provenance and peer review Not commissioned; internally peer reviewed.

(C) Author(s) (or their employer(s)) 2020. No commercial re-use. See rights and permissions. Published by BMJ.

A) Check for updates
To cite L'Imperio V, Vischini G, Pagni F, et al. Ann Rheum Dis Epub ahead of print: [please include Day Month Year]. doi:10.1136/annrheumdis-2020-217979

Received 14 May 2020

Accepted 15 May 2020

\section{Glinked}

http://dx.doi.org/10.1136/annrheumdis-2020-218035

Ann Rheum Dis 2020;0:1-2. doi:10.1136/annrheumdis-2020-217979

\section{ORCID iD}

Vincenzo L'Imperio http://orcid.org/0000-0002-9284-2998

\section{REFERENCES}

1 Gercik O, Bilgin E, Solmaz D, et al. Histopathological subgrouping versus renal risk score for the prediction of end-stage renal disease in ANCA-associated vasculitis. Ann Rheum Dis 2020;79:675-6.

2 Brix SR, Noriega M, Tennstedt $P$, et al. Development and validation of a renal risk score in ANCA-associated glomerulonephritis. Kidney Int 2018;94:1177-88.

3 Berden AE, Ferrario F, Hagen EC, et al. Histopathologic classification of ANCAassociated glomerulonephritis. J Am Soc Nephrol 2010;21:1628-36.

4 Hauer HA, Bajema IM, Van Houwelingen HC, et al. Determinants of outcome in ANCAassociated glomerulonephritis: a prospective clinico-histopathological analysis of 96 patients. Kidney Int 2002;62:1732-42.

5 Trimarchi H, Barratt J, Cattran DC, et al. Oxford Classification of IgA nephropathy 2016: an update from the IgA Nephropathy Classification Working Group. Kidney Int 2017:91:1014-21.

6 Bajema IM, Wilhelmus S, Alpers CE, et al. Revision of the International Society of Nephrology/Renal pathology Society classification for lupus nephritis: clarification of definitions, and modified National Institutes of health activity and chronicity indices. Kidney Int 2018;93:789-96.

7 Working Group of the International IgA Nephropathy Network and the Renal Pathology Society, Roberts ISD, Cook HT, et al. The Oxford classification of IgA nephropathy: pathology definitions, correlations, and reproducibility. Kidney Int 2009;76:546-56.

8 Haas M, Loupy A, Lefaucheur C, et al. The Banff 2017 kidney meeting report: revised diagnostic criteria for chronic active T cell-mediated rejection, antibody-mediated rejection, and prospects for integrative endpoints for next-generation clinical trials. Am J Transplant 2018;18:293-307.

9 Kriz W, LeHir M. Pathways to nephron loss starting from glomerular diseases-insights from animal models. Kidney Int 2005;67:404-19. 